http://ojs.borneo.ac.id/ojs/index.php/JBKB

ISSN 2685-0753 (cetak) ISSN 2685-2039 (online)

\title{
TEKNIK RESTRUKTURISASI KOGNITIF UNTUK MEREDUKSI KECEMASAN SOSIAL REMAJA
}

\author{
Novita Riyanti \\ Email: novitariyanti11@gmail.com
}

\begin{abstract}
Abstrak
Salah satu tugas perkembangan masa remaja adalah mencapai hubungan baru yang lebih matang baik antar individu ataupun kelompok. Salah satu kesulitan yang dialami remaja adalah yang berhubungan dengan penyesuaian sosial. Ketika remaja tidak dapat menempatkan diri dengan baik dilingkungan sosial, maka akan berdampak negatif bagi dirinya dan lingkungan sekitarnya pun dianggap negatif, ketika tanggapan negatif tersebut terus dipertahankan, maka akan menimbulkan kecemasan sosial pada remaja. Beberapa literatur menunjukkan bahwa salah satu teknik yang dapat membantu remaja mengurangi kecemasan sosial yaitu teknik restrukturisasi kognitif. Kajian ini membahas tentang kecemasan sosial, aspek-aspek kecemasan sosial, faktor penyebab kecemasan sosial, teknik restrukturisasi kognitif, tujuan teknik restrukturisasi kognitif dan implementasi teknik restrukturiasai kognitif untuk mereduksi kecemasan sosial remaja. Hasil kajian menunjukkan bahwa teknik restrukturisasi kognitif dapat membantu mengkoreksi kepercayaan yang salah atau menyimpang yang mengakibatkan remaja berfikir tidak rasional dan menggantinya dengan cara berfikir yang lebih rasional.
\end{abstract}

Kata Kunci : kecemasan sosial; teknik restrukturisasi kognitif; remaja

\section{PENDAHULUAN}

Masa remaja merupakan tahap perkembangan antara masa anak-anak dan masa dewasa yang ditandai oleh perubahan fisik umum serta perkembangan kognitif dan sosial (Hurlock 2004, hlm. 206). Berkaitan dengan perkembangan remaja, perlu disadari bahwa proses perkembangan itu terjadi melalui pengalaman belajar. Salah satu tugas perkembangan pada masa remaja yaitu memiliki kesadaran tanggungjawab sosial. Tidak seperti masa kanak-kanak, pada masa remaja perkembangan sosial nya semakin luas. Pada masa remaja, mereka tidak hanya berteman dengan lingkungan sekitar, tetapi mereka memiliki keinginan untuk mencari teman dilingkungan yang lebih luas.

Perkembangan

sosial mempengaruhi remaja dalam hubungan sosialnya, seperti dengan teman sebaya, lingkungan dan orang tua. Kehidupan sosial pada usia remaja mulai menunjukkan ketertarikan untuk bergabung dengan lingkungan sosial serta menurut Herbert, T.B (2001, hlm 39) pada masa remaja menjadi tahap perkembangan identitas yang penting 
dan pengembangan keterampilan sosial, dimana kekhawatiran tentang penerimaan teman menjadi hal yang paling penting. Ketika memasuki masa remaja, salah satu kesulitan yang dialami remaja adalah yang berhubungan dengan penyesuaian sosial (Hurlock 2002, hlm. 213). Remaja dituntut harus menyesuaikan diri dengan lingkungan, terutama lingkungan sekolah dan lingkungan teman sebaya. Pada masa remaja cenderung untuk mengikuti pendapat orang lain, nilai, kebiasaan serta keinginan orang lain, hal ini dapat memberikan dampak yang positif maupun negatif bagi remaja. Apabila remaja dapat menempatkan diri dengan baik di tengah-tengah realita, maka remaja dapat menghadapi kenyataan kehidupan dengan penuh kebenaran, tetapi apabila remaja tidak dapat menerima realita yang terjadi dikehidupannya, maka akan berdampak negatif bagi dirinya dan lingkungan sekitarnya pun dianggap negatif bagi dirinya.

Menurut Sriarti (2008, hlm. 34) tanggapan negatif dapat menjadikan remaja hidup dalam ketakutan yang akan mempengaruhi seluruh alam perasaannya sehingga terjadi keguncangan dalam keseimbangan kepribadian, yaitu suatu keadaan emosi yang labil. Maka dalam keadaan labil remaja tidak dapat berpikir secara wajar dan segala sesuatu yang berada di dalam dan di luar diri dipersepsikan secara salah. Keadaan labil yang dialami remaja semakin lama tidak dapat dipertahankan lagi, yang akhirnya akan menimbulkan kecemasan sosial.

Di Indonesia, hasil penelitian Suryaningrum (2006) di Universitas Muhammadiyah Malang menunjukkan dari 211 partisipan mahasiswa $22,27 \%$ mengalami gangguan kecemasan sosial $21,28 \%$ sangat membutuhkan bantuan,
$20,85 \%$ terindikasi memunculkan gejala gangguan, $56,87 \%$ tidak dapat didagnosis mengalami gangguan kecemasan sosial. Selain itu hasil Penelitian Beidel \& Morris 1995 (dalam Bukowski, H. M 1997, p. 338) menemukan bahwa anak-anak yang didiagnosis dengan kecemasan sosial melaporkan bahwa $60 \%$ situasi sosial mereka yang menyedihkan terjadi di lingkungan sekolah dengan kejadian yang paling menyedihkan adalah pertemanan dengan teman sebaya yang tidak baik atau tidak akrab. Dengan kata lain bahwa kecemasan sosial yang sering terjadi yaitu dilingkungan sekolah bersama dengan teman-teman.

Remaja yang mengalami kecemasan sosial biasanya memiliki cara berfikir yang irasional terhadap dirinya sendiri dan orang lain. Remaja berfikir ketika dia mengatakan dan melakukan suatu tindakan akan dinilai negatif oleh orang lain, ketika pemikiran tersebut muncul, maka akibatnya remaja akan semakin menjauhi interaksi sosial dengan orang lain.

Berdasarkan uraian di atas, perlu adanya solusi untuk membantu memperbaiki fungsi berfikir remaja yang irasional menjadi lebih rasional agar tidak terjadi gangguan psikologis pada remaja. Upaya tersebut dapat dilakukan melalui teknik restrukturisasi kognitif, yang bertujuan untuk mengubah atau mengganti pikiran yang irasional menjadi pikiran yang rasional.

Sejalan dengan penelitian yang dilakukan oleh Anggia, M.I (2018) menyatakan bahwa ketika siswa diberikan layanan konseling kelompok dengan teknik restrukturisasi kognitif, maka kecemasan siswa dalam menghadapi ujian semakin menurun.

Atas dasar tersebut, perlu pemikiran lebih lanjut yaitu : 
"bagaimana mengimplementasikan teknik restrukturisasi kognitif'. Konsep tersebut bertujuan untuk membantu mengatasi kesalahan fungsi berfikir remaja terhadap sesuatu yang akan berpengaruh terhadap perilaku yang akan ditunjukkan oleh remaja.

\section{METODE}

Tulisan ini bersifat library research (penelitian/studi pustaka), dengan mengumpulkan data dan informasi berdasarkan kajian ilmiah dalam buku, hasil penelitian, dan jurnal ilmiah. Output dari artikel ini adalah memberikan konstribusi pemikiran mengenai teknik restrukturisasi kognitif untuk mereduksi kecemasan sosial remaja.

\section{PEMBAHASAN Kecemasan Sosial}

Kecemasan sosial adalah seseorang yang mengalami ketakutan, rasa gugup, dan kekhawatiran yang dirasakan saat melakukan interaksi sosial dengan orang lain. Kecemasan sosial "menyerang" fikiran individu, contohnya jika remaja melakukan sesuatu, remaja itu akan diberi label negatif oleh orang lain atau berpikir dirinya akan melakukan sesuatu yang dapat membuat dirinya malu dihadapan orang lain (Butler, G. 2008, hlm. 1).

American Psychiatric Association (APA) mengungkapkan bahwa kecemasan sosial adalah ketakutan yang menetap terhadap satu (atau lebih) situasi sosial yang terkait dan berhubungan dengan performa, yang membuat individu harus berhadapan dengan orang-orang yang tidak dikenalnya atau menghadapi kemungkinan diamati oleh orang lain, takut bahwa dirinya akan dipermalukan atau dihina (La Greca, 1998). Menurut Arkowitz (1975, hlm. 211-221) masalah yang sering dialami oleh individu dengan gangguan kecemasan sosial adalah merasa tidak nyaman saat melakukan interaksi sosial.

Cederlund (2013) mengungkapkan bahwa $17 \%$ remaja yang memiliki ketakutan sosial sering menghindari situasi sosial. Menurut Philippe et al (2013, hlm. 301) hal ini dapat menyebabkan rusaknya fungsi sosial, pendidikan, dan pekerjaan. Bhan, K. P. et al (2009, hlm. 393) juga berpendapat bahwa gangguan kecemasan sosial dapat melumpuhkan individu dengan kemungkinan terjadi pengangguran, terhambatnya sosialisasi seseorang, dan ketidakpuasan terhadap kehidupan serta kesehatan.

Di kanada yang mengalami gangguan kecemasan sosial pertahunnya diperkirakan sebesar 8\%, sedangkan di provinsi Nova Scotia mengalami gangguan kecemasan sosial pertahunnya diperkirakan 4,2\% (Bhan, K. P. et al., 2009, hlm. 394).

Orang-orang yang memiliki kecemasan sosial cenderung dianggap tidak menarik oleh orang lain, kurang kredibel, dan sangat jarang menduduki jabatan pemimpin. Dampak yang ditimbulkan pada pekerjaan seseorang akan menjadi tidak puas akan hasil kerjanya, disekolah individu cenderung malas, baik malas dalam belajar ataupun berinteraksi dengan orang lain (Rakhmat, 2011, hlm. 107). Menurut penelitian yang dilakukan, gangguan kecemasan sosial tidak begitu mendapat perhatian khusus karena gangguan tersebut masih dianggap wajar, kecuali gangguan tersebut berlanjut dimana siswa menolak untuk sekolah (beidel \& morris, 1995).

$\begin{array}{rcc}\text { Dapat } & \text { disimpulkan } & \text { bahwa } \\ \text { kecemasan } & \text { sosial } & \text { adalah }\end{array}$


ketakutan/kekhawatiran untuk berinteraksi dengan orang lain yang disebabkan karena individu tersebut beranggapan bahwa ia akan mendapatkan kritikan dan hinaan dari orang lain, yang mengakibatkan seseorang tersebut menjadi pemurung, pendiam, dan tidak ada keberanian untuk berbicara didepan umum.

\section{Aspek-Aspek Kecemasan Sosial}

Ada tiga asek kecemasan sosial menurut (La Greca, 1998, hlm. 88) yaitu: (1) ketakutan akan evaluasi negatif. Individu yang mengalami gangguan kecemasan sosial akan takut terhadap penilaian negatif dari orang lain dan lingkungan sekitarnya, dan individu yang mengalami gangguan kecemasan sosial juga akan menilai dirinya dengan penilaian yang negatif apabila harapan yang diinginkannya tidak dapat terpenuhi; (2) penghindaran sosial dan rasa tertekan dalam situasi yang baru atau berhubungan dengan orang asing atau baru. Individu yang mengalami gangguan kecemasan sosial akan merasa tidak nyaman, gugup dan malu ketika berada dalam situasi yang baru atau asing bagi dirinya; (3) penghindaran sosial dan rasa tertekan yang dialami secara umum atau dengan orang yang dikenal. Individu yang mengalami gangguan kecemasan sosial akan merasa tidak nyaman dan tidak percaya diri saat melakukan interaksi dengan orang yang sudah dikenalnya. Faktor Penyebab Kecemasan Sosial

Hofmann (2010, hlm. 226-239) menyebutkan ada tiga faktor yang dapat menyebabkan kecemasan sosial yaitu: (1) faktor genetik. Hanya 5\% faktor genetik sebagai penyebab kecemasan sosial sehingga pengaruh gen masih dianggap sangat kecil terhadap kecemasan sosial yang dialami individu; (2) faktor orang tua. Anak-anak yang cemas cenderung memiliki orang tua dengan perilaku yang cemas pula. Serta tidak peka nya orang tua terhadap gangguan yang dialami anak akan mempengaruhi tingkat kecemasan sosial yang dialami remaja.

\section{Teknik Restrukturisasi Kognitif}

Konsep kognitif perilaku diadaptasi dari Cognitive Behavioral Therapy (CBT) yang bersumber dari psikologi behavior pada awal abad ke 20 (McLeod, J 2008, hlm. 139). Restrukturisasi kognitif merupakan salah satu teknik dari konseling kognitif perilaku yang dikemukakan oleh Aaron Beck, yang dipandang oleh beberapa ahli sebagai teknik yang lebih integratif dan merupakan teknik yang memiliki pengaruh dari pendekatan cognitive therapy dan behavioral therapy. Terapi kognitif meliputi mengubah cara berfikir, kepercayaan, sikap, asumsi, imajinasi dan memfasilitasi individu belajar mengenali dan mengubah kesalahan dalam aspek kognitif, sedangkan aspek behavioral meliputi mengubah hubungan yang salah antara situasi permasalahan dengan kebiasaan mereaksi permasalahan, belajar mengubah perilaku, menenangkan pikiran dan tubuh sehingga merasa lebih baik serta berfikir lebih jelas (Rusmana 2017, hlm. 84).

Restrukturisasi kognitif merupakan alternatif teknik dari konseling kognitif perilaku yang telah dikembangkan oleh beberapa ahli kognitif perilaku, seperti Michael Mahoney dan Donald Meichenbaum. Teknik restrukturisasi kognitif pada dasarnya meyakini pola pemikiran manusia terbentuk melalui proses stimulus-kognisi-respon (SKR) yang saling berkaitan dan membentuk semacam jaringan SKR dalam otak manusia, dimana proses kognitif menjadi faktor penentu dalam 
menjelaskan bagaimana manusia berfikir, merasa dan bertindak

(Oemarjoedi 2003, hlm. 6).

\section{Tujuan Teknik}

\section{Restrukturisasi Kognitif}

Menurut Ranta, K. et al (2015, hlm.

230) tujuan teknik restrukturisasi kognitif adalah untuk beralih dari pemikiran yang tidak realistis ke pemikiran yang lebih realistis dan membantu remaja lebih efektif untuk mengelola kecemasannya, yang paling terpenting dari teknik restrukturisasi kognitif adalah bukan hanya untuk mencapai pemikiran yang positif saja tetapi mencapai pemikiran yang realistis. Proses pemikiran realistis melibatkan langkah-langkah berikut : (1) mengidentifikasi peristiwa/ situasi yang menyebabkan terjadinya kecemasan; (2) mengidentifikasi pemikiran dibalik terjadinya kecemasan; (3) mengevaluasi seberapa realistis pemikiran itu, misalnya dengan mencari bukti; (4) mempertimbangkan seberapa realistis konsekuensi yang diharapkan; (5) mengidentifikasi pemikiran realistis untuk mengganti pemikiran yang tidak realistis.

\section{Implementasi Teknik \\ Restrukturisasi Kognitif Untuk Mereduksi Kecemasan Sosial Remaja}

Agar dapat secara efektif menggunakan teknik restrukturisasi kognitif, seorang remaja harus terlebih dahulu memahami hubungan antara pemikiran dan perasaan/perilaku. Cara remaja berfikir akan mempengaruhi perasaannya dan akan mempengaruhi tindakannyanya (Ranta, K. et al 2015, hlm. 231). Ketika remaja mengalami kecemasan sosial, remaja mengidentifikasi pemikiran seperti orang lain akan berfikir buruk tentang saya, saya akan melakukan sesuatu yang memalukan, semua orang akan menertawakan saya, padahal pemikiran negatif yang dipikirkan remaja tersebut belum tentu orang lain juga memikirkan hal tersebut.

Adapun tahapan restrukturisasi kognitif menurut (Dobson \& Dobson 2009, hlm. 117-129) sebagai berikut: (1) assesmen dan diagnosa. Assesmen dan diagnosa ditahap awal bertujuan untuk memperoleh data tentang kondisi konseli yang akan ditangani serta mengantisipasi kemungkinan kesalahan penanganan pada proses konseling; (2) mengidentifikasi pikiran-pikiran negatif remaja. Sebelum konseli diberikan bantuan untuk mengubah pikiran-pikiran yang mengalami disfungsi, konselor terlebih dahulu perlu membantu konseli untuk menyadari disfungsi pikiranpikiran yang konseli miliki dan memberitahukan secara langsung kepada konselor; (3) memonitor pikiranpikiran negatif remaja melalui Thought Record (rekaman pikiran).

Berikut adalah format "Thought Record" yang diberikan kepada konseli untuk mencatat pikiran-pikiran negatif konseli; (4) intervensi pikiran-pikiran negatif remaja menjadi pikiran-pikiran yang positif. Dobson \&Dobson (2009, hlm. 127) menyatakan bahwa langkah intervensi pikiran-pikiran negatif diberikan kepada konseli apabila konselor sudah mendapatkan banyak informasi mengenai pikiran-pikiran negatif konseli itu sendiri setelah terkumpul dalam Thought Record.

\section{SIMPULAN}

Kecemasan sosial pada remaja terjadi karena pikiran irasional yang diciptakan oleh remaja itu sendiri. Ketika remaja merasa takut, khawatir, malu, gugup, dan tidak percaya diri, kemungkinan besar hal tersebut disebabkan karena remaja memiliki pikiran irasional terhadap dirinya sendiri 
maupun reaksi orang lain terhadap dirinya.

Untuk membantu mengatasi kecemasan sosial yang dialami remaja, salah satu teknik yang dapat dilakukan yaitu menggunakan teknik restrukturisasi kognitif, karena tujuan dari teknik restrukturisasi kognitif adalah untuk mereduksi kecemasan sosial yang berfokus pada kognitif yang menyimpang akibat individu tidak mampu mengelola ketakutannya ketika melakukan interaksi sosial dengan orang lain.

\section{REFERENSI}

Anggia, M.I (2018). Efektivitas Layanan Konseling Kelompok Teknik Restrukturisasi Kognitif untuk Mereduksi Kecemasan Mneghadapi Ujian Siswa Kelas VII SMP N 22 Kota Bengkulu. Jurnal Ilmiah Bimbingan dan Konseling, 1 (2), 1-10. https://ejournal.unib.ac.id

Arkowitz, J. V. (1975). Social Anxiety and Self-Evaluation of Interpersonal Performance. Psychological Reports, 36 (1), 211221.

https://doi.org/10.2466/pr0.1975.3 $\underline{6.1 .211}$

Bhan, K. P. et al. (2009). Social Anxiety in a Multiple Sclerosis Clinic Population. Multiple Sclerosis, 15 (3), 393-398. https://doi.org/10.1177/13524585 $\underline{08099143}$

Bieling, P. J, et al. (2006). CognitiveBehavioral Therapy in Groups. New York: The Guilford Press.

Beidel, D. C. et al. (1995). A New Inventory to Assess Child Social
Phobia: the Social Phobia and Anxiety Inventory for Children. Psychological Assessment, 7 (1), 73-79.

https://www.researchgate.net/publ ication $/ 230642840$

Butler, G. (2008). Overcoming Social Anxiety and Shynes: A Self-helf Guide using Cognitive Behavioral Techniques. New York: Basic Book.

Cederlund, R. (2013). Social Anxiety Disorder in Children and Adolescents: Assesment, Maintaining Faktors, and Treatment. Stockholm, Sweden: Dapertement of Psychology, Stockholm University.

Dobson, D \& Dobson, K. S. (2009). Evidance-based Practice of Cognitive Behavioral Therapy. New York: The Guilford Press.

Herbert, T. B. (2001). Social Anxiety Disorder in Childhood and Adolescent: Current Status and Future Directions. Clinical Child and Family Psychology Review, 4 (1), 37-61. https://doi.org/10.1023/A:100957 $\underline{6610507}$

Hurlock, E.B. (2004). Psikologi Perkembangan. Jakarta: PT. Gelora Aksara Pratama.

Hurlock, E.B. (2002). Alih Bahasa oleh Istiwidayanti \& Soedjarwo. Psikologi Perkembangan. Edisi ke 5. Jakarta: Erlangga.

Hofman, S. G. (2010). Social Anxiety: Clinical, Developmental, and

Social Perspectives, Second Edition. London : Academic Press, Elsevier. 
La Greca, A. M. \& Lopez, N. (1998).

Social Anxiety Among Adolescents: Linkages with Peer Relations and Friendships. Journal of Abnormal Child Psychology, 26 (2), 83-94. https://doi.org/10.1023/A:102268 $\underline{4520514}$

McLeod, J. (2008). Alih Bahasa oleh

A.K. Anwar. Pengantar Konseling : Teori dan Studi Kasus. Jakarta: Kencana.

Oemarjoedi, A. K. (2003). Pendekatan Cognitive Behavior Dalam Psikoterapi. Jakarta: Kreatif media.

Rakhmat, J. (2011). Psikologi Komunikasi. Bandung: PT.

Remaja Rosdakarya.

Ranta, K. et al (2015). Social Anxiety and Phobia in Adolescents. New York: Springer International Publishing Switzerland.

Rusmana, N. (2017). Bimbingan dan Konseling Kelompok di Sekolah. Bandung: rizqi press.

Sriarti, A. (2008). Tinjauan Tentang Stres.

http://digilib.unsri.ac.id/TINJAU AN\%20TENTANG\%20STRES.p df

Suryaningrum, C. (2016). Efikasi Diri dan Kecemasan Sosial: Studi Meta Analisis. Jurnal Ilmiah Psikologi Terapan, 04 (02), 182193. http://www.umm.ac.id/index.php/ jipt/ 